\title{
Primary Malignant Melanoma of the Breast
}

Jiwon $\mathrm{Koh}^{1} \cdot$ Jihyeon $\mathrm{Lee}^{2}$

So Youn Jung ${ }^{3} \cdot$ Han Sung Kang ${ }^{3}$

Tak Yun ${ }^{4} \cdot$ Youngmee Kwon ${ }^{2,3}$

'Department of Pathology, Seoul National

University College of Medicine, Seoul;

${ }^{2}$ Department of Pathology, National Cancer

Center, Goyang; ${ }^{3}$ Center for Breast Cancer,

National Cancer Center, Goyang; ${ }^{4}$ Center for

Specific Organs Center, National Cancer Center,

Goyang, Korea

Received: September 26, 2018

Revised: October 13, 2018

Accepted: October 18, 2018

\section{Corresponding Author}

Youngmee Kwon, MD, PhD

Department of Pathology, National Cancer Center,

323 Ilsan-ro, Ilsandong-gu, Goyang 10408, Korea

Tel: +82-31-920-1742

Fax: +82-31-920-1369

E-mail:ymk@ncc.re.kr
Primary malignant melanoma of the breast (PMMB) is a rare tumor with only a few case reports available in the literature. We report two cases of PMMB, one derived from the breast parenchyma and the other from the breast skin. The first case consisted of atypical epithelioid cells without overt melanocytic differentiation like melanin pigments. The tumor cells showed diffuse positivity for S100 protein, tyrosinase, and BRAF V600E. However, the tumor cells were negative for cytokeratin, epithelial membrane antigen, and HMB-45. The second case showed atypical melanocytic proliferation with heavy melanin pigmentation. The tumor cells were positive for S100 protein, HMB-45, tyrosinase, and BRAF V600E. These two cases represent two distinct presentations of $\mathrm{PMMB}$ in terms of skin involvement, melanin pigmentation, and $\mathrm{HMB}-45$ positivity. Although PMMB is very rare, the possibility of this entity should be considered in malignant epithelioid neoplasms in the breast parenchyma.

Key Words: Breast; Malignant melanoma; BRAF
Malignant melanoma is the malignant neoplasm of melanocytes which occurs predominantly in the skin, and about 4\%-5\% of primary melanomas arise from noncutaneous sites including mucous membranes, gastrointestinal tract, and leptomeninges. ${ }^{1,2}$ Primary malignant melanoma of the breast (PMMB) is particularly rare, accounting for less than $0.5 \%$ of breast cancers and $3 \%-5 \%$ of malignant melanoma of all tissue types. ${ }^{3,4}$ Only six cases of PMMB derived from the breast parenchyma without skin involvement have been reported in the literature, ${ }^{5}$ whereas less than 190 cases have been reported from the skin overlying the breast. ${ }^{4}$

PMMB can present as either (1) parenchymal melanoma without skin involvement ${ }^{5}$ or (2) cutaneous melanoma involving the skin overlying the breast. ${ }^{6}$ Here, we describe two cases of PMMB, one of each type. This case study was approved by the Institutional Review Board of National Cancer Center with a waiver of informed consent (IRB No. NCC 2018-0183).

\section{CASE REPORT}

Case 1 was a 70-year-old female who presented with her right palpable breast mass. There were no abnormal findings on the overlying skin, and magnetic resonance imaging (MRI) of the breast revealed a $2.1 \mathrm{~cm}$ single enhancing mass on the deep portion of the right upper inner quadrant (Fig. 1A). No hypermetabolic lesion suggesting distant metastasis was noted on positron emission tomography (PET) (Fig. 1B). The differential diagnosis of malignant epithelioid neoplasms such as sarcomatoid carcinoma, sarcoma with epithelioid features or malignant melanoma was considered by core needle biopsy. The patient underwent right breast-conserving surgery and sentinel lymph node biopsy uneventfully. Gross examination showed a $2.1 \mathrm{~cm}$ solid gray-white mass with an expanding border within the breast parenchyma (Fig. 1C). No discernable lesion was noted on the overlying skin. On microscopic examination, the tumor showed a solid growth pattern with partial peripheral rimming of lymphoid cells (Fig. 1D). It also contained some scattered lymphoid cells in the central portion with focal tumor necrosis (Fig. IE). The 

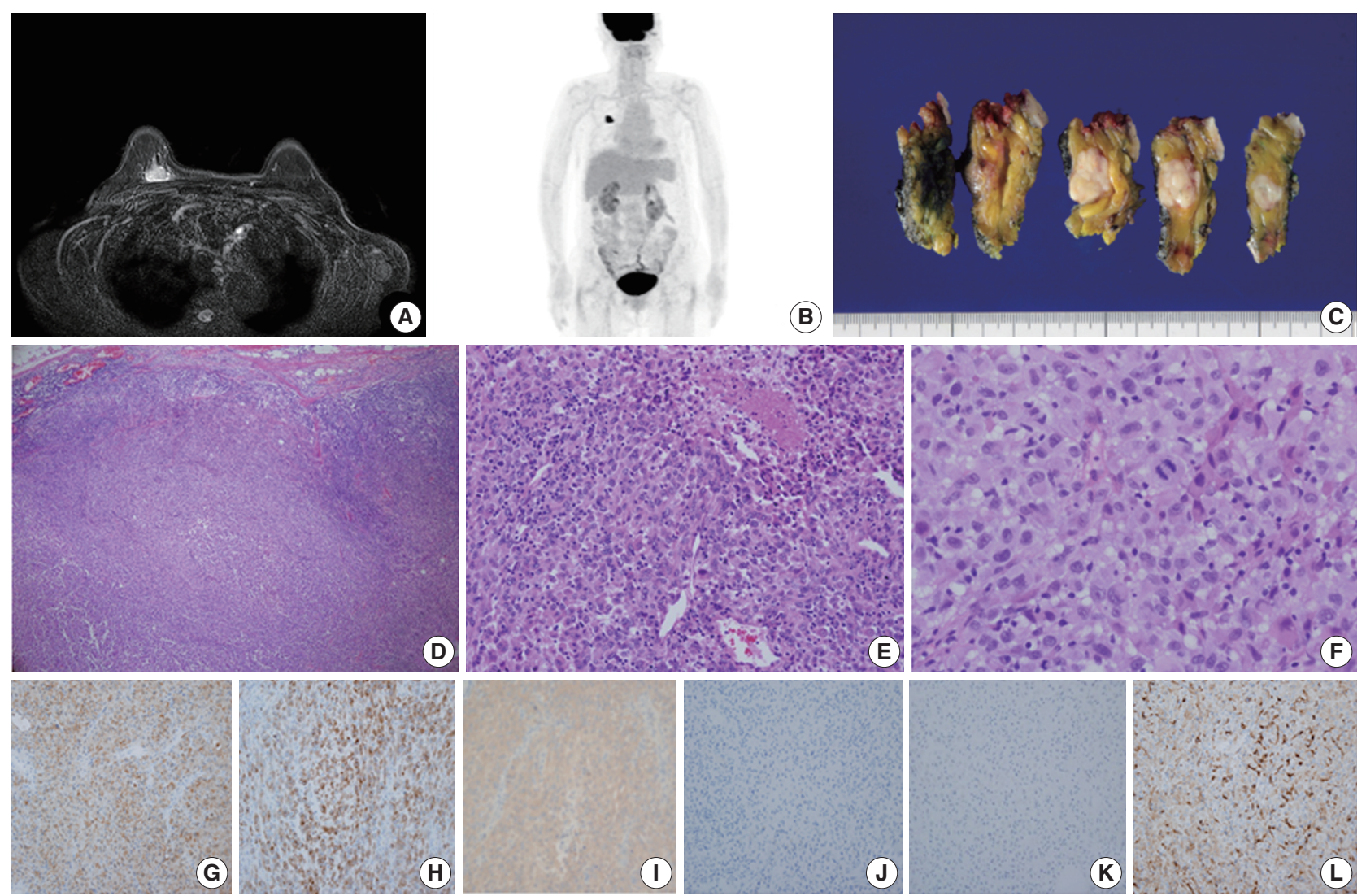

Fig. 1. (A, B) Breast magnetic resonance imaging (A) and positron emission tomography scan (B) show a solitary breast mass without regional or distant metastasis. (C) Gross examination reveals a grayish white solid mass within the breast parenchyma without skin involvement. (D-F) Microscopically, the tumor shows solid growth pattern (D) and focal tumor necrosis (E), consisting of atypical epithelioid cells. (GL) The tumor cells are diffusely positive for $\mathrm{S} 100$ protein $(\mathrm{G})$ and tyrosinase $(\mathrm{H})$ and weakly positive for BRAF V600E $(\mathrm{I})$, while they are negative for HMB-45 (J) and cytokeratin (K) with nonspecific weak staining for CD68 (L).

tumor consisted of polygonal epithelioid cells with abundant eosinophilic cytoplasm and oval eccentric nuclei (Fig. 1F). The tumor cells exhibited significant nuclear pleomorphism and occasional mitoses (up to 10/10 high-power field). No overt features of melanocytic differentiation such as melanin pigments were noted. By immunohistochemistry (IHC), the tumor cells showed diffuse positivity for $\mathrm{S} 100$ protein, tyrosinase, and BRAF V600E, despite HMB-45 negativity (Fig. 1G-J). The tumor cells were negative for epithelial markers such as cytokeratin (CK) (Fig. 1K), low molecular weight $\mathrm{CK}$, high molecular weight $\mathrm{CK}$, and epithelial membrane antigen. Furthermore, BRAF V600E mutation was confirmed by real-time polymerase chain reaction using a peptide nucleic acid clamping method (Supplementary Fig. S1). Therefore, the final diagnosis was primary noncutaneous malignant melanoma of the breast (PNCMB). Four sentinel lymph nodes were negative for metastasis. After a follow-up of 23 months, multiple metastases involving the left neck, left adrenal gland, left thigh muscle, and peritoneum were noted on PET scan. Since the discovery of metastases, the patient has received immune checkpoint inhibitor therapy for three months.

Case 2 was a 30-year-old female who had a wart-like lesion on her left breast skin since childhood that recently rapidly increased to $3.0 \mathrm{~cm}$ in size. Breast MRI showed only mild thickening and enhancement of the left breast skin (Fig. 2A). No abnormal lesion other than that of the breast skin was observed during systemic workup studies including PET scan (Fig. 2B). Left breast-conserving surgery and axillary lymph node dissection were performed. On gross examination, the dark brown-colored skin lesion measured $4.5 \mathrm{~cm}$ in its greatest dimension, and no abnormal lesion within the breast parenchyma was noted on serial sections (Fig. 2C). On microscopic examination, atypical melanocytic proliferation with heavy pigmentation was observed (Fig. 2D). The lesion displayed an invasive front extending to the reticular dermis (Clark level IV), measuring $0.2 \mathrm{~cm}$ in thickness. The tumor cells stained positive for $\mathrm{S} 100$ protein, tyrosinase, HMB-45, and BRAF V600E but negative for CK by IHC (Fig. 2E-I). Thus, 

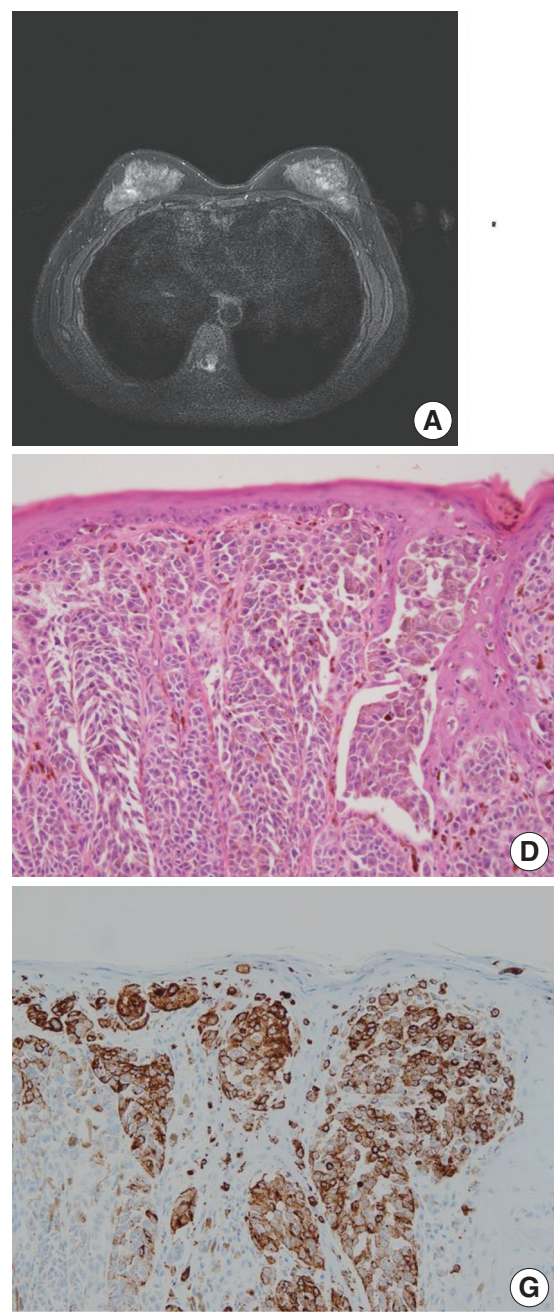

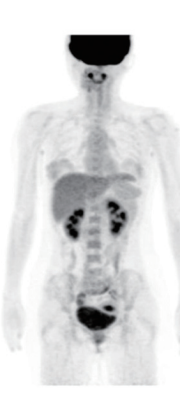

(B)
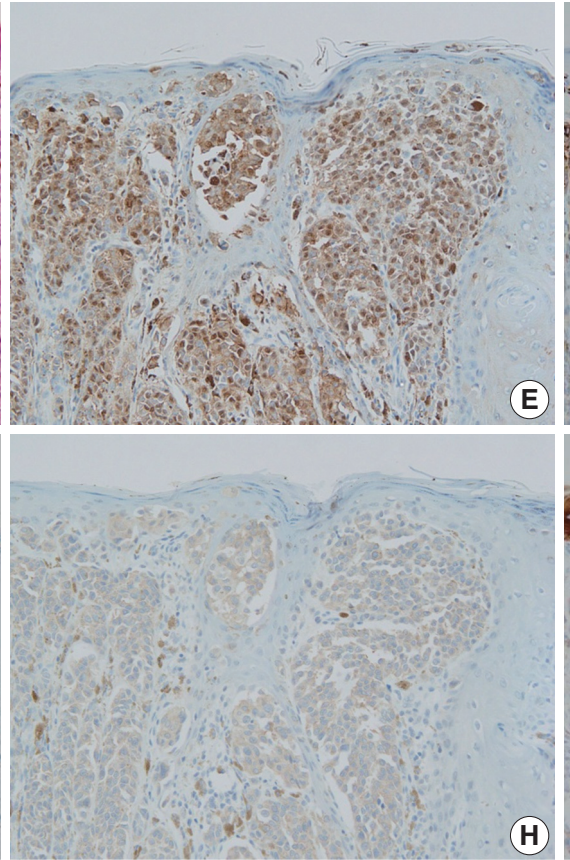
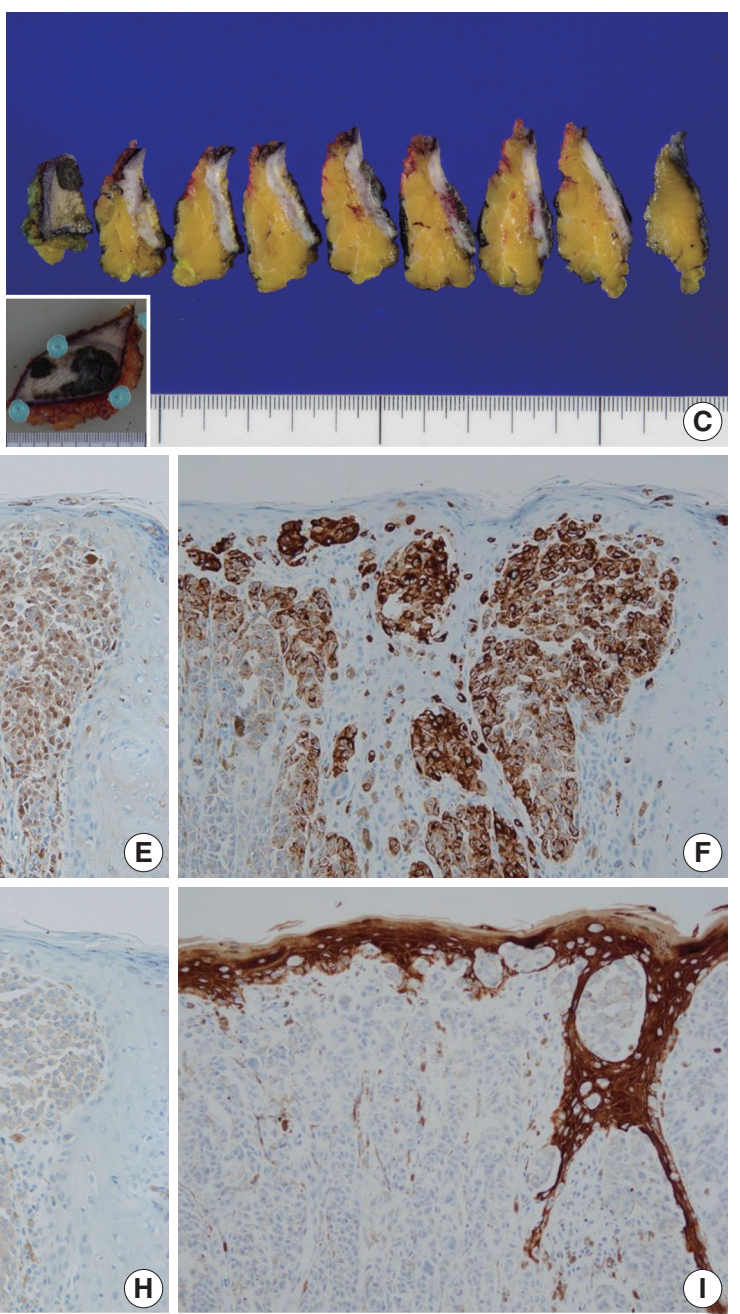

Fig. 2. (A, B) No remarkable findings other than mild thickening of the left breast skin are seen on breast magnetic resonance imaging (A) or positron emission tomography scan (B). (C) Gross examination reveals a relatively demarcated dark brown lesion. (D) Microscopically, the tumor is composed of atypical melanocytic proliferation with melanin pigmentation. (E-l) The tumor cells are strongly positive for S100 protein (E), tyrosinase (F), and HMB-45 (G); weakly positive for BRAF V600E (H); but negative for cytokeratin (I).

the diagnosis was primary cutaneous malignant melanoma of the breast (PCMB). Lymph node metastasis was identified in one of 19 axillary lymph nodes. At 8-month follow-up appointment, lung and bone metastases were detected with computed tomography and bone scans. Immune checkpoint inhibitor therapy was recommended, but the patient refused the treatment and was lost to follow-up.

\section{DISCUSSION}

Malignant melanomas occurring in the breast can be classified into three categories: (1) primary noncutaneous melanomas of the breast parenchyma, (2) primary cutaneous melanomas of the skin overlying the breast, and (3) metastatic melanomas to the breast from other cutaneous locations. ${ }^{5}$ PMMB involving the breast skin or parenchyma is rare across the globe, but metastatic melanomas to the breast are observed with varying frequencies. For example, metastatic melanoma to the breast from other skin locations is the most common metastatic tumor to the breast in the United States ${ }^{7}$ but not in Korea. ${ }^{8}$ Fewer than 190 cases of PCMB have been reported, while only a few cases of PNCMB have been reported in the literature. ${ }^{5}$ We present two cases of PMMB with distinct presentation in terms of skin involvement, melanin pigmentation, and HMB-45 positivity. Their clinicopathologic characteristics are summarized in Table 1.

While it is known to be rare, the exact incidence of PMMB is unknown. ${ }^{4}$ PNCMB is exceedingly rare. Rassouli and Voutsadakis ${ }^{5}$ have reported that there are only six cases of PNCMB in 
Table 1. Clinicopathologic features of two cases of primary malignant melanoma of the breast

\begin{tabular}{lll}
\hline & \multicolumn{1}{c}{ Case 1 } & \multicolumn{1}{c}{ Case 2 } \\
\hline Age (yr) & 70 & 30 \\
Sex & Female & Female \\
Location of tumor & $\begin{array}{l}\text { Right breast parenchyme } \\
\text { Upper inner quadrant }\end{array}$ & Left breast skin \\
Key histologic features & Atypical epithelioid cells & Atypical melanocytes \\
& No pigmentation & Heavy pigmentation \\
& (amelanotic) & \\
Size of tumor (cm) & 2.1 & 4.5 \\
Depth of invasion (mm) & NA & 2 \\
Sentinel lymph node & Negative & Positive \\
status & & \\
IHC & Negative & \\
CK & Negative & Negative \\
EMA & Positive & NA \\
Vimentin & Positive & Positive \\
S100 protein & Negative & Positive \\
HMB-45 & Positive & Positive \\
Tyrosinase & Positive & Positive \\
BRAF V600E & PNCMB & PCsitive \\
Pathologic diagnosis & PNB \\
\hline
\end{tabular}

$\mathrm{NA}$, not applicable; $\mathrm{IHC}$, immunohistochemistry; CK, cytokeratin; EMA, epithelial membrane antigen; HMB-45, human melanoma black-45; BRAF, rapidly accelerated fibrosarcoma (RAF) kinase-related oncogene homolog B; PNCMB, primary noncutaneous melanoma of the breast; PCMB, primary cutaneous melanoma of the breast.

the English literature. Due to the rarity of PNCMB, its clinicopathology is largely unknown, leading to diagnostic difficulty. Differential diagnoses include sarcomatoid carcinoma and sarcoma with epithelioid features such as clear cell sarcoma and histiocytic sarcoma.

Considering its low incidence, poorly differentiated invasive breast carcinoma is the first to be ruled out during diagnosis. Some authors have reported rare cases of metaplastic carcinoma with melanocytic differentiation, characterized by a melanocytic portion that lacks keratin staining but is positive for $\mathrm{S} 100$ protein and HMB-45, in the midst of a CK-positive metaplastic carcinoma area. ${ }^{9}$ However, the first case in our report exhibits no evidence of epithelial differentiation, further supported by total IHC negativity for $\mathrm{CK}$, low molecular weight $\mathrm{CK}$, and high molecular weight $\mathrm{CK}$, which is in contrast with previous reports about metaplastic carcinoma with melanocytic differentiation.

One difficulty in the differential diagnosis of our first case was the interpretation of $\mathrm{S} 100$ protein positivity with HMB-45 negativity by IHC. There have been reports of $S 100$ protein positivity in some metaplastic carcinoma and basal-type breast cancers. ${ }^{10}$ Additionally, many studies focused on the immunohistochemical features of melanoma have demonstrated that HMB- 45 has the lowest sensitivity (albeit with high specificity) among the ma- jor melanocytic markers such as $\mathrm{S} 100$ protein, HMB-45, Melan$\mathrm{A}$, and tyrosinase. ${ }^{11}$ In addition, previous studies have suggested that HMB-45 is less sensitive in amelanotic melanomas. ${ }^{12}$ Therefore, when PMMB is suspected, use of multiple melanocytic markers would be useful for enhancing the diagnostic yield.

Clear cell sarcoma is well-known for its histology, which is almost identical to that of malignant melanoma. There have been efforts to find the ideal biomarker for differentiating these two entities, and some recent studies have suggested that the presence of $B R A F$ mutation favors the diagnosis of melanoma over clear cell sarcoma. ${ }^{13}$ Case 1 in this study showed positivity for BRAF V600E by IHC, implying BRAF mutation ${ }^{14}$ and supporting the diagnosis of malignant melanoma.

Histiocytic sarcoma is also included in differential diagnoses of PNCMB due to the histologic features such as a polygonal nucleus and abundant eosinophilic cytoplasm with indistinct cell borders. However, the positivity of melanocytic markers is an important finding for the diagnosis of PNCMB, despite nonspecific weak CD68 staining, as in our case (Fig. 1L).

The most notable features of the second case presented here compared to the first case are skin involvement and overt melanocytic differentiation with heavy pigmentation. These characteristic findings clearly support the diagnosis of PCMB; however, it is also recommended that IHC be performed to rule out the possibility of its mimicker, pigmented mammary Paget disease. Pigmented Paget disease accounts for a minute portion of mammary Paget disease. Pagetoid spread of malignant epithelial cells with pigmentation can indicate cutaneous melanoma or pigmented mammary Paget disease. ${ }^{15}$ However, IHC for melanocytic markers and epithelial markers can distinguish malignant melanoma from pigmented mammary Paget disease.

It is interesting to see that both our PNCMB and PCMB cases were positive for BRAF V600E by IHC. Furthermore, the BRAF $\mathrm{V} 600 \mathrm{E}$ mutation was also confirmed in case 1 by real-time polymerase chain reaction using the peptide nucleic acid clamping method. To date, only two other cases of PNCMB have been tested for $B R A F$ mutation, and one case reported by Rassouli and Voutsadakis ${ }^{5}$ had a BRAF V600E mutation. ${ }^{4}$ Our first case is the second reported case of PNCMB with BRAF mutation. The clinicopathologic features of PNCMB reported in the English literature are summarized in Table 2 and are compared to the case reported here. ${ }^{5,16-19}$ Case 1 presented here and the previously reported BRAF mutant PMMB case have some additional features in common: both are solitary amelanotic tumors confined to the breast parenchyma, show positivity for $\mathrm{S} 100$ protein by IHC, have no evidence of primary melanoma except the breast on systemic workup stud- 
Table 2. Summary of clinicopathologic features of PNCMB reported in the English literature by comparison with our case

\begin{tabular}{|c|c|c|c|c|c|c|c|c|}
\hline \multirow{2}{*}{ Case No. } & \multirow{2}{*}{ Study } & \multirow{2}{*}{ Age (yr) } & \multirow{2}{*}{ Size $(\mathrm{cm})$} & \multirow{2}{*}{ Histology } & \multicolumn{2}{|c|}{$\mathrm{IHC}$} & \multirow{2}{*}{$\begin{array}{c}\text { BRAF } \\
\text { mutations }\end{array}$} & \multirow{2}{*}{ LN status } \\
\hline & & & & & Positive & Negative & & \\
\hline 1 & Bernardo et al. ${ }^{16}$ & 76 & 2.5 & $\begin{array}{l}\text { Meshwork of spindle cells with } \\
\text { heavy granular pigmentation }\end{array}$ & NA & NA & NA & No \\
\hline 2 & Roy et al. ${ }^{17}$ & 40 & 3.0 & $\begin{array}{l}\text { Large pleomorphic cells with } \\
\text { vesicular nucleus and single } \\
\text { prominent nucleolus, } \\
\text { moderate eosinophillic } \\
\text { cytoplasm }\end{array}$ & $\begin{array}{l}\text { S100 protein } \\
\text { HMB-45 } \\
\text { Vimentin }\end{array}$ & $\begin{array}{l}\text { CK } \\
\text { EMA } \\
\text { CHR } \\
\text { SYN } \\
\text { SMA } \\
\text { ER, PR, HER2 }\end{array}$ & NA & No \\
\hline 3 & Biswas et al. ${ }^{18}$ & 32 & 4.0 & $\begin{array}{l}\text { Abundant clear cytoplasm and } \\
\text { large vesicular nucleus with } \\
\text { prominent nucleolus, } \\
\text { no pigment }\end{array}$ & $\begin{array}{l}\text { S100 protein } \\
\text { HMB-45 }\end{array}$ & $\begin{array}{l}\text { CK } \\
\text { EMA } \\
\text { Vimentin } \\
\text { SMA }\end{array}$ & NA & No \\
\hline 4 & He et al..$^{19}$ & 26 & 3.0 & $\begin{array}{l}\text { Round or oval cells with large } \\
\text { nuclei and abundant cytoplasm, } \\
\text { no significant pigmentation }\end{array}$ & $\begin{array}{l}\text { S100 protein } \\
\text { HMB-45 } \\
\text { Melan A }\end{array}$ & $\begin{array}{l}\text { CK } \\
\text { EMA } \\
\text { Vimentin } \\
\text { SMA } \\
\text { ER, PR, HER2 }\end{array}$ & NA & Yes \\
\hline 5 & Drueppel et al. ${ }^{4}$ & 54 & 10.0 & Undifferentiated histology & $\begin{array}{l}\text { S100 protein } \\
\text { Melan A } \\
\text { Vimentin }\end{array}$ & $\begin{array}{l}\text { HMB-45 } \\
\text { Desmin } \\
\text { Actin } \\
\text { CD34 }\end{array}$ & Negative & No \\
\hline 6 & $\begin{array}{l}\text { Rassouli and } \\
\text { Voutsadakis }^{5}\end{array}$ & 50 & 1.2 & $\begin{array}{l}\text { Irregular cells with abundant } \\
\text { amelanotic cytoplasm and } \\
\text { prominent nucleoli }\end{array}$ & $\begin{array}{l}\text { S100 protein } \\
\text { HMB-45 } \\
\text { Melan A }\end{array}$ & $\begin{array}{l}\text { ER } \\
\text { PR } \\
\text { p63 }\end{array}$ & Positive & No \\
\hline Present case & & 70 & 2.1 & $\begin{array}{l}\text { Polygonal epithelioid cells with } \\
\text { eosinophilic cytoplasm and } \\
\text { oval eccentric nucleus, } \\
\text { no significant pigmentation }\end{array}$ & $\begin{array}{l}\text { S100 protein } \\
\text { Tyrosinase } \\
\text { Vimentin }\end{array}$ & $\begin{array}{l}\text { CK } \\
\text { EMA } \\
\text { HMB-45 }\end{array}$ & Positive & No \\
\hline
\end{tabular}

PNCMB, primary noncutaneous melanoma of the breast; $I \mathrm{HC}$, immunohistochemistry; BRAF, rapidly accelerated fibrosarcoma (RAF) kinase-related oncogene homolog B; LN, lymph node; NA, not applicable; HMB-45, human melanoma black-45; CK, cytokeratin; EMA, epithelial membrane antigen; CHR, chromogranin; SMA, smooth muscle actin; ER, estrogen receptor; PR, progesterone receptor; HER2, human epidermal growth factor receptor 2.

ies, and were diagnosed at an early stage without nodal involvement. The presence of BRAF mutation in PMMB cases suggests that PMMB may have similar pathogenesis with typical malignant melanoma, and that PMMB may also be eligible for targeted therapy such as BRAF inhibitors.

Pathogenesis of PNCMB is not yet well-defined. Some authors have suggested that it may be a metastatic tumor from an unknown primary or a primary tumor that has completely regressed. ${ }^{17}$ Others have proposed that it may be a true primary tumor arising from ectopic melanocytes in the breast epithelium. Metaplastic transformation of a normal mammary duct precursor could be another alternative pathogenic pathway. ${ }^{5}$

In summary, we report two cases of PMMB with distinct clinical manifestations. Since PMMB is a very rare tumor in the breast, it can be a diagnostic challenge for pathologists. PNCMB can present as an amelanotic neoplasm without skin involvement, so it should be included in the differential diagnosis of poorly differentiated neoplasms within the breast parenchyma. The cocktail IHC of multiple melanocytic markers is a crucial ancillary test for the diagnosis of PMMB, and BRAF V600E IHC may also be helpful for both diagnosis and therapy.

\section{Electronic Supplementary Material}

Supplementary materials are available at Journal of Pathology and Translational Medicine (http://jpatholtm.org).

\section{ORCID}

Jiwon Koh: https://orcid.org/0000-0002-7687-6477

Tak Yun: https://orcid.org/0000-0001-9540-0397

Youngmee Kwon: https://orcid.org/0000-0002-1370-2496

\section{Author Contributions}

Conceptualization: YK.

Data curation: JK, YK.

Formal analysis: JK, YK.

Investigation: JK, JL, SYJ, HSK, TY, YK.

Writing一original draft: JK, YK.

Writing—review \& editing: JK, JL, SYJ, HSK, TY, YK. 


\section{Conflicts of Interest}

The authors declare that they have no potential conflicts of interest.

\section{REFERENCES}

1. Hussein MR. Extracutaneous malignant melanomas. Cancer Invest 2008; 26: 516-34.

2. McLaughlin CC, Wu XC, Jemal A, Martin HJ, Roche LM, Chen VW. Incidence of noncutaneous melanomas in the U.S. Cancer 2005; 103: 1000-7.

3. Kurul S, Tas F, Buyukbabani N, Mudun A, Baykal C, Camlica H. Different manifestations of malignant melanoma in the breast: a report of 12 cases and a review of the literature. Jpn J Clin Oncol 2005; 35: 202-6.

4. Drueppel D, Schultheis B, Solass W, Ergonenc H, Tempfer CB. Primary malignant melanoma of the breast: case report and review of the literature. Anticancer Res 2015; 35: 1709-13.

5. Rassouli M, Voutsadakis IA. Primary noncutaneous malignant melanoma of the breast. Breast J 2016; 22: 688-91.

6. Alzaraa A, Sharma N. Primary cutaneous melanoma of the breast: a case report. Cases J 2008; 1: 212.

7. Williams SA, Ehlers RA 2nd, Hunt KK, et al. Metastases to the breast from nonbreast solid neoplasms: presentation and determinants of survival. Cancer 2007; 110: 731-7.

8. Oh YL, Ko YH. Fine needle aspiration cytology of metastatic melanoma in the breast: a case report. Korean J Cytopathol 1998; 9: 111-6.

9. Bendic A, Bozic M, Durdov MG. Metaplastic breast carcinoma with melanocytic differentiation. Pathol Int 2009; 59: 676-80.
10. Liu D, Rudland PS, Sibson DR, Platt-Higgins A, Barraclough R. Expression of calcium-binding protein S100A2 in breast lesions. $\mathrm{Br}$ J Cancer 2000; 83: 1473-9.

11. Blessing K, Sanders DS, Grant JJ. Comparison of immunohistochemical staining of the novel antibody melan-A with $\mathrm{S} 100$ protein and HMB-45 in malignant melanoma and melanoma variants. Histopathology 1998; 32: 139-46.

12. Ohsie SJ, Sarantopoulos GP, Cochran AJ, Binder SW. Immunohistochemical characteristics of melanoma. J Cutan Pathol 2008; 35: 433-44.

13. Yang L, Chen $Y$, Cui T, et al. Identification of biomarkers to distinguish clear cell sarcoma from malignant melanoma. Hum Pathol 2012; 43: 1463-70.

14. Long GV, Wilmott JS, Capper D, et al. Immunohistochemistry is highly sensitive and specific for the detection of V600E BRAF mutation in melanoma. Am J Surg Pathol 2013; 37: 61-5.

15. Petersson F, Ivan D, Kazakov DV, Michal M, Prieto VG. Pigmented Paget disease: a diagnostic pitfall mimicking melanoma. Am J Dermatopathol 2009; 31: 223-6.

16. Bernardo MM, Mascarenhas MJ, Lopes DP. Primary malignant melanoma of the breast. Acta Med Port 1980; 2: 39-43.

17. Roy S, Dhingra K, Mandal S, Khurana N. Unusual presentation of metastatic amelanotic melanoma of unknown primary origin as a solitary breast lump. Melanoma Res 2008; 18: 447-50.

18. Biswas A, Goyal S, Jain A, et al. Primary amelanotic melanoma of the breast: combating a rare cancer. Breast Cancer 2014; 21: 236-40.

19. He Y, Mou J, Luo D, Gao B, Wen Y. Primary malignant melanoma of the breast: a case report and review of the literature. Oncol Lett 2014; 8: 238-40. 